Jurnal Hukum Mimbar Justitia

Fakultas Hukum Universitas Suryakancana

Vol. 6 No. 1 - Juni 2020, hlm. 71-89.

ISSN: 2477-5681 (Cetak), ISSN: 2580-0906 (Online)

Open Access at: https://jurnal.unsur.ac.id/jmj

\title{
REGULASI PENDIDIKAN KARAKTER BAGI MAHASISWA DI FAKULTAS HUKUM UNIVERSITAS SURYAKANCANA DALAM RANGKA MENINGKATKAN SOFTSKILL DAN LITERASI KEUANGAN
}

\author{
Tanti Kirana Utami \\ Universitas Suryakancana \\ Email: kireinatanti78@gmail.com
}

\author{
M. Rendi Aridhayandi \\ Universitas Suryakancana \\ Email: mrendiaridhayandi@unsur.ac.id
}

Masuk: Maret 2020

Penerimaan: April 2020

Publikasi: Juni 2020

\begin{abstract}
ABSTRAK
Moralitas dan karakter mahasiswa menjadi sorotan ketika mengalami erosi, maka pendidikan karakter yang telah diajarkan bukan hanya sebagai sebuah teori pembelajaran tetapi sebuah praktik kehidupan mahasiswa ketika belajar di kampus. Melalui pengembangan kurikulum yang inovatif yang tujuan untuk meningkatkan keterampilan melalui pelatihan peningkatan soft skill dan keuangan bagi mahasiswa sangat penting sekali karena dalam Kegiatan Pelatihan tersebut mahasiswa dapat lebih meningkatkan keterampilan hidup (soft skills) dan keterampilan pengelolaan keuangan yang dapat mendukung kesiapan mahasiswa dalam memasuki pasar kerja maupun dunia usaha, yang kemudian dapat membantu meningkatkan kesejahteraan ekonominya di masa mendatang dengan program pelatihan peningkatan soft skill dan keuangan atau Financial Life Skill (FLS). Fakultas Hukum Universitas Suryakancana merujuk pada berbagai peraturan perundang-undangan yang berlaku, yang dtuangkan dalam bentuk surat keputusan Dekan mengenai kompetensi lulusan.
\end{abstract}

Kata Kunci : Financial Life Skill (FLS), Karakter, Moralitas, Pelatihan Peningkatan Soft Skill.

\section{ABSTRACT}

Student morality and character are in the spotlight when experiencing erosion, so character education that has been taught is not only a learning theory but a practice of student life when studying on campus. Through the development of an innovative curriculum that aims to improve skills through training to improve student soft skills and finance is very important because in these training activities students can further improve life skills (soft skills) and financial management skills that can support student readiness to enter the job market. and the business world, which can then help 
improve their economic welfare in the future with a training program to improve soft skills and finance or Financial Life Skills (FLS). The Faculty of Law, Suryakancana University refers to various applicable laws and regulations, which are set forth in the form of a Dean's decree regarding graduate competence.

Keywords: Financial Life Skill (FLS), Character, Morality, Training Soft Skills Improvement.

\section{PENDAHULUAN}

Isu yang sekarang terjadi adalah kekhawatiran sebagian orang bahwa karakter bangsa sedang mengalami erosi. Isu pembangunan karakter adalah adalah konsekuensi logis dari degradasi kecerdasan berbangsa. Untuk memperbaiki moralitas dan karakter mahasiswa, maka pendidikan karakter yang telah diajarkan bukan hanya sebagai sebuah teori pembelajaran tetapi sebuah praktik kehidupan mahasiswa ketika belajar di kampus. Sudah saatnya pendidikan karakter di perguruan tinggi berfungsi membendung degradasi moralitas atau karakter dan membentuk karakter mahasiswa yang kokoh guna menghadapi berbagai tantangan masa depan. Pendidikan karakter pun menjadi daya pendorong bagi para mahasiswa untuk menjadi intelektual muda bangsa yang memiliki kepribadian unggul, sebagaimana dimuat dalam undang-undang pendidikan nasional.

Menurut Schaeffer, pendidikan karakter adalah proses panjang untuk membantu mahasiswa mengembangkan karakter seperti mengetahui, perduli, dan bertindak berdasarkan nilai-nilai etika utama seperti; keadilan, kejujuran, bertanggung jawab, dan penghargaan pada diri sendiri dan orang lain. Mahasiswa dengan karakter yang kuat pada akhirnya akan meningkatkan mutu pendidikan nasional. ${ }^{1}$

Mahasiswa sebagai insan masa depan perlu untuk dibentuk karakternya. Pembentukan karakter melalui perguruan tinggi ini sangat

Sukmawati dalam Monica Mayeni Manurung dan Rahmadi, 2017, Identifikasi Faktor-Faktor Pembentukan Karakter Mahasiswa, Jurnal Analisis Sistem Pendidikan Tinggi, VOL. 1 NO. 1, Forum Dosen Indonesia, hlm. 42. 
Tanti Kirana Utami dan M. Rendi Aridhayandi

Jurnal Hukum Mimbar Justitia

Vol. 6 No. 1 - Juni 2020

tidak mudah untuk melihat hasilnya dalam masa mahasiswa masih mengikuti perkuliahan, akan tetapi hasil pembentukan tersebut bukan tidak mungkin terlihat pada detik-detik akhir mahasiswa akan menyelesaikan pendidikannya di bangku perkuliahan. Yang menjadi pertanyaan adalah, kapankah waktu yang tepat mengidentifikasi karakter mahasiswa, sebagai langkah awal yang sangat penting untuk dilakukan demi mempersiapkan sumber daya yang selain memiliki karakter secara akademis juga memiliki karakter sebagai manusia seutuhnya. ${ }^{2}$

Dalam perspektif pendidikan, aspek intelektual dan moral tidak bisa dipisahkan dari pembentukan karakter individu. Kebaikan intelektual menyiapkan kondisi mental dimana individu dapat memahami dan memilih suatu orientasi secara benar. Demikian pula, kebaikan moral akan menshahihkan tindakan-tindakan yang baik sehingga menjadi ciri kepribadian dalam berperilaku. Pembentukan karakter mahasiswa secara formal dilakukan dengan upaya menyiapkan kondisi, sarana/prasarana, kegiatan, pendidikan dan kurikulum yang mengarah kepada pembentukan watak dan budi pekerti generasi muda bangsa memiliki landasan yuridis yang kuat. ${ }^{3}$

Pendidikan karakter mengajarkan kebiasaan cara berpikir dan berperilaku sehingga mereka mampu hidup dan bekerjasama dengan keluarga, masyarakat, negara, dan membantu mereka dalam membuat keputusan yang tepat. Karena pendidikan karakter tidak bisa dibentuk secara instan maka mahasiswa harus dilatih secara serius, berkelanjutan dan seimbang untuk mencapai karakter yang ideal. ${ }^{4}$

Pengembangan karakter sangat penting dilakukan oleh perguruan tinggi dan stakeholders-nya untuk menjadi pijakan dalam penyelenggaraan pendidikan karakter di perguruan tinggi. Tujuan pendidikan karakter pada dasarnya adalah untuk mendorong lahirnya manusia yang baik, yang memiliki kepribadian menarik, beretika,

Ibid,.

4 Susanti R, 2013, Penerapan Pendidikan Karakter di Kalangan Mahasiswa, Jurnal AlTa'lim, Vol. 1 No. 6, hlm. 480-487. 
Tanti Kirana Utami dan M. Rendi Aridhayandi

Jurnal Hukum Mimbar Justitia

Vol. 6 No. 1 - Juni 2020

bersahaja, jujur, cerdas, peduli, dan tangguh. Tumbuh dan berkembangnya karakter yang baik akan mendorong peserta didik tumbuh dengan kapasitas dan komitmen untuk melakukan berbagai hal yang terbaik dan melakukan segalanya dengan benar dan memiliki tujuan hidup. ${ }^{5}$

Pendidikan karakter membentuk pribadi bermoral dengan menciptakan struktur dan lingkungan yang membantu pertumbuhan moral individu. Hal ini mewajibkan masyarakat untuk mengaktualisasikan pendidikan karakter di dalam lembaga pendidikan. Pendidikan karakter memerlukan kepercayaan yang mendalam, bahwa manusia berkembang bukan hanya memenuhi panggilan kodratnya dalam kehidupan bersama didalam masyarakat, melainkan menanggapi tawaran kodratinya sebagai makhluk mampu

5 Konstantinus Dua Dhiu dan Nikodemus Bate, 2017, Pentingnya Pendidikan Karakter Di Perguruan Tinggi Kajian Teoritis Praktis, 2nd Annual Proceeding, November, (ISSN: 2355-5106), STKIP Citra Bakti, Bajawa, NTT, hlm. 173. mengatasi diri, melalui kebebasan dan pemikirannya. ${ }^{6}$

Peran serta semua pihak terkait sangat dibutuhkan dalam pendidikan karakter mahasiswa. Lembaga pendidikan tinggi berperan menciptakan iklim akademik yang menunjang dan pengembangan kurikulum yang mendukung pembentukan karakter mahasiswa. Sistem pendidikan dan sarana penunjang menjadi bagian dari upaya pengembangan atmosfer akademik. Dosen melakukan tugas dan tanggung jawab profesinya dalam penerapan pembentukan karakter mahasiswa.

Pemerintah memiliki peran penting dalam menyertakan pendidikan karakter dalam peraturan perundangundangan. Hal ini telah dilakukan, salah satunya seperti yang tertuang dalam Undang-Undang Republik Indonesia Nomor 12 Tahun 2012 tentang Pendidikan Tinggi. Sistem

6 Sukmawati F, 2016, Peran Kejujuran Akademik (Academic Honesty) dalam Pendidikan Karakter Studi pada Mahasiswa Jurusan Bimbingan Konseling Islam Fakultas Ushuludin Adab dan Dakwah Angkatan 2013/2014, Jurnal Khatulistiwa - Journal of Islamic Studies, Vol. 6 No. 1, hlm. 87-100. 
Tanti Kirana Utami dan M. Rendi Aridhayandi

Jurnal Hukum Mimbar Justitia

Vol. 6 No. 1 - Juni 2020

pendidikan tinggi juga harus selalu dievaluasi agar dapat mengikuti perkembangan jaman dan perubahan perilaku atau karakter mahasiswa.

Pendidikan tidak hanya sebatas mentransfer ilmu pengetahuan saja, namun lebih dari itu, yakni bagaimana dapat mengubah atau membentuk karakter dan watak seseorang agar menjadi lebih baik, mempunyai skill yang mumpuni, lebih sopan dalam tataran etika dan estetika, serta yang lebih penting adalah perilaku dalam kehidupan sehari-hari.

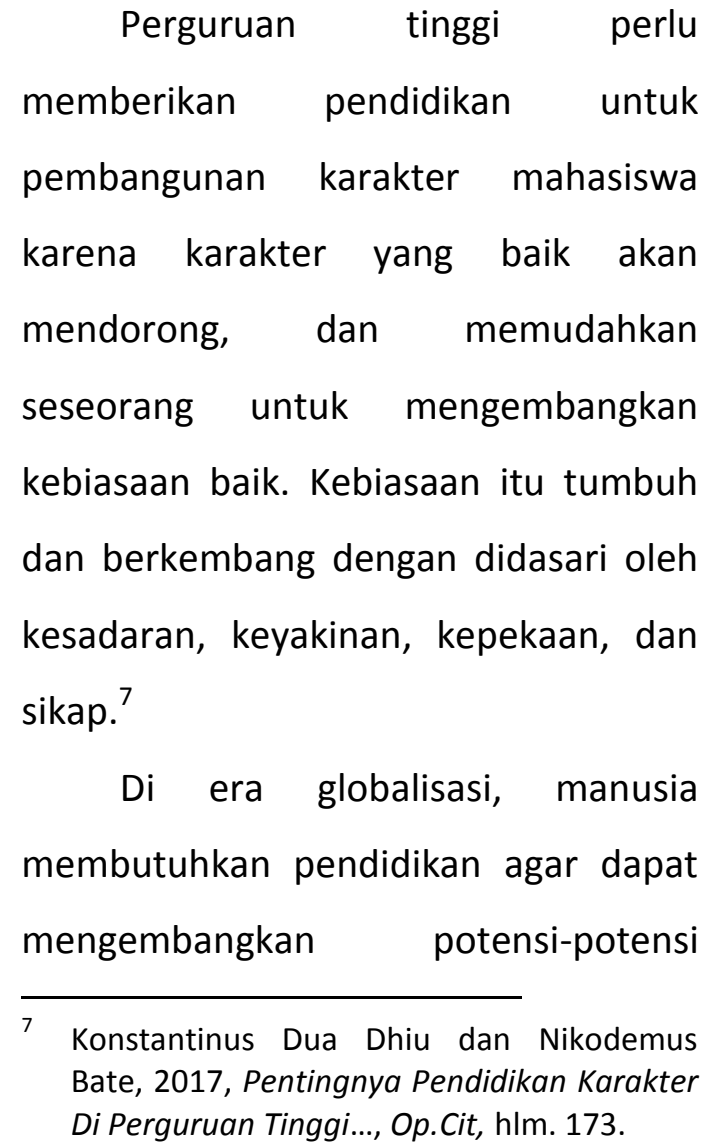

dirinya, agar tercipta sumber daya yang berkualitas. Pendidikan dalam hal ini merupakan suatu proses agar peserta didik memiliki pengetahuan (kognitif), sikap (afektif) dan keterampilan (psikomotor) guna bekal hidup ditengah-tengah masyarakat. ${ }^{8}$

Membahas mengenai upaya peningkatan softskill mahasiswa di Fakultas Hukum Universitas Suryakancana sangat luas sekali, untuk itu penulis membatasinya pada hal-hal sebagai berikut:

1. Apa Latar Belakang Perlunya Pendidikan Karakter Bagi Mahasiswa?

2. Bagaimana Regulasi Pendidikan Karakter Bagi Mahasiswa Di Fakultas Hukum Universitas Suryakancana?

8 Sudrajat A., 2017, Psikologi Pendidikan, PEAP Press, Kuningan, hlm. 25, vide dalam Firdaus, 2017, Urgensi Soft Skill dan Character Building Bagi Mahasiwa, Jurnal TAPIs, Vol. 14 No. 01 Januari - Juni, hlm. 6061. 
II. PEMBAHASAN

\section{A. Pendidikan Karakter Bagi Mahasiswa}

Kinerja sistem beserta komponen yang mendukung kehidupan manusia tidak semata-mata didasari oleh keberadaan peralatan yang ada, tetapi dorongan dari manusia untuk mengaktualisasikan kemampuannya. Dorongan dari dalam diri manusia ini juga disebut dengan kemampuan soft skill. Jadi, soft skill tidak semata-mata kemampuan manajerial yang berorientasi hanya pada upaya efisiensi dan efektifitas, tetapi juga bagaimana mampu mengelola agar manusia yang berposisi sebagai pendukung sistem mempunyai kepuasan psikologis.

Berdasarkan hasil beberapa jajak pendapat (tracer study) yang dilakukan beberapa perguruan tinggi di Indonesia, kompetensi sarjana di dunia kerja dibagi dua aspek yakni hard skill dan soft skill. Soft skill sangat terkait erat dengan masalah kecerdasan emosi. Kecerdasan emosi merupakan kemampuan seseorang untuk memotivasi diri sendiri, bertahan menghadapi frustrasi, mengendalikan dorongan hati dan tidak melebihlebihkan kesenangan, mengatur suasana hati dan mampu mengendalikan stress.

Selain masalah karakter penting bagi mahasiswa untuk memiliki bekal soft skill untuk terjun di dunia kerja setelah menyelesaikan pendidikan di perguruan tinggi. Saat ini, mahasiswa begitu sangat menginginkan pencapaian Indeks Prestasi Kumulatif (IPK) yang sangat tinggi. Mereka beranggapan bahwa, jika mempunyai Indeks Prestasi Kumulatif yang sangat tinggi, akan mempermudah jalan mereka diterima bekerja di Perusahaan yang mereka idamkan. Hal itu tidaklah salah dan juga tidak terlalu tepat untuk beranggapan demikian. Nyatanya saat ini, Perusahaan tidak selalu melihat mahasiswa dengan predikat IPK tinggi, tetapi perusahaan juga melihat dari indeks yang lain. Indeks yang lain itu ialah bagaimana mahasiswa mempunyai kemampuan soft skills yang baik. $^{9}$

Fatchul Mu`in, 2011, Pendidikan Karakter Konstruksi Teoritik \& Praktik, Ar-Ruzz Media, Yogyakarta, hlm. 11, vide dalam Firdaus, 2017, Urgensi Soft skill dan 
Tanti Kirana Utami dan M. Rendi Aridhayandi

Jurnal Hukum Mimbar Justitia

Vol. 6 No. 1 - Juni 2020

Soft skills adalah keterampilan seseorang dalam berhubungan dengan orang lain (interpersonal skills) dan keterampilan dalam mengatur dirinya sendiri (intrapersonal skills) untuk kerja secara maksimal. Berthal mengemukakan Soft skills diartikan sebagai perilaku personal dan interpersonal yang mengembangkan dan memaksimalkan kinerja manusia. Sedangkan menurut Putra dan Pratiwi soft skills adalah kemampuankemampuan tak terlihat yang diperlukan untuk sukses, misalnya kemampuan berkomunikasi, kejujuran/integritas dan lain-lain. ${ }^{10}$

Pola pembelajaran yang berientasi pada karakter ini nantinya mampu menstimulasi mahasiswa sejak dini sehingga akan terbentuk watak yang mengandung nilai-nilai kemuliaan sehingga akan terwujud sumber daya insani yang berkualitas. Hal ini sesuai dengan program pemerintah yakni telah meluncurkan "pembangunan

Character Building Bagi Mahasiwa, Jurnal TAPIs Vol. 14 No. 01.

10 Putra, Ikhsan S., dan Aryanti Pratiwi, 2005, Sukses dengan Soft Skills, ITB, Bandung, hlm. 5 . karakter untuk mendorong kesadaran dan pentingnya membangun peradaban bangsa". ${ }^{11}$

Pendidikan karakter di perguruan tinggi tidak dapat ditawar lagi dewasa ini. Salah satu unsur yang terlibat dalam pendidikan karakter adalah dosen. Dalam proses pembelajaran di kelas seorang dosen tidak hanya menyampaikan materi pembelajaran, tetapi juga harus menjiwai seluruh proses pembelajaran dengan nilai-nilai luhur seperti kejujuran, keterbukaan, saling menghargai, tanggung jawab, dan sebagainya. Di sini seorang dosen dapat dikatakan sebagai dosen yang berkarakter. $^{12}$

Pentingnya Pendidikan Karakter di Perguruan Tinggi Fenomena atau kasus menyontek yang dilakukan oleh para mahasiswa sebenarnya menjadi pekerjaan rumah bagi para dosen.

11 Isroah, Sukanti dan Ani Widayati, 2013, Implementasi Pendidikan Karakter Dalam Perkuliahan Perpajakan Pada Mahasiswa Jurusan Pendidikan Akuntansi, Universitas Negeri Yogyakarta, Jurnal Pendidikan Akuntansi Indonesia, Vol. Xl, No. 1, hlm. 101.

12 Devi Syukri Azhari Dan Alaren, 2017, Peran Dosen Dalam Mengembangkan Karakter Mahasiswa, Jutnal Pelangi, Vol. 9 No.2, hlm. 91. 
Tanti Kirana Utami dan M. Rendi Aridhayandi

Jurnal Hukum Mimbar Justitia

Vol. 6 No. 1 - Juni 2020

Fenomena ini menunjukkan bahwa pendidikan karakter yang diajarkan belum menyentuh kehidupan praktis mahasiswa. Para mahasiswa yang menghidupi budaya instan sebenarnya telah menunjukkan degradasi moralitas. Mereka hanya mencari kesenangan sendiri tanpa memahami sebuah perjuangan, kesabaran, kesetiaan, dan nilai kejujuran. Untuk memperbaiki moralitas dan karakter mahasiswa, maka pendidikan karakter yang telah diajarkan bukan hanya sebagai sebuah teori pembelajaran tetapi sebuah praktik kehidupan mahasiswa ketika belajar di kampus. Sudah saatnya pendidikan karakter di perguruan tinggi berfungsi membendung degradasi moralitas atau karakter dan membentuk karakter mahasiswa yang kokoh guna menghadapi berbagai tantangan masa depan. $^{13}$

\section{Jarot Tri Wibowo Santoso} mengatakan Kemerosotan karakter anak bangsa ini merupakan hasil dari output dunia pendidikan yang lebih mementingkan kognitif dibanding

13 Ibid., hlm. 90. afektif. Artinya sekolah lebih mementingkan kepandaian dibandingkan karakter atau proses yang jujur, dan berdasar karakter yang luhur. Akibatnya tidak jarang banyak sekolah yang mengejar tingkat kelulusan 100\% dengan cara yang tidak benar. ${ }^{14}$

Pendidikan yang seharusnya menjadi alternatif untuk mengatasi dan mencegah krisis karakter bangsa. Kondisi tersebut menyadarkan akan pentingnya pendidikan karakter khususnya bagi mahasiswa sebagai calon-calon pemimpin bangsa di masa yang akan datang Pada hakekatnya pendidikan merupakan suatu pembentukan dan pengembangan karakter manusia secara menyeluruh, yakni pembentukan dan pengembangan potensi ilmiah yang ada pada diri manusia secara menyeluruh, sehingga manusia mampu menghadapi setiap perubahan yang terjadi. Dalam rangka pembangunan manusia

14 Jarot Tri Bowo Santoso, 2013, Karakter Dan Pemahaman Pendidikan Karakter Mahasiswa Pendidikan Akuntansi Melalui Pembelajaran Strategi Belajar Mengajar Berkarakter, Jurnal Pendidikan Ekonomi Dinamika pendidikan, Vol. VIII, No. 1, Juni, hlm. 11. 
Tanti Kirana Utami dan M. Rendi Aridhayandi Jurnal Hukum Mimbar Justitia Vol. 6 No. 1 - Juni 2020

Indonesia seutuhnya, pembangunan di bidang pendidikan merupakan sarana dan wahana yang sangat baik dalam pembinaan sumber daya manusia. Oleh karena itu, dalam proses pendidikan disamping menekankan pada ilmu pengetahuan (kognitif) juga diarahkan pada pengembangan sumber daya manusia yang memiliki karakter untuk dapat belajar cepat dengan terampil dalam melaksanakan sesuatu (psikomotor), serta diarahkan pada pengembangan sikap mental dan karakter untuk terjun di masyarakat (afektif). ${ }^{15}$

Kondisi di terus berlangsung tiap tahun sehingga memunculkan kelompok mahasiswa terbagi sebagai berikut:

1. Kelompok Mahasiswa Kupu-kupu (kuliah pulang-kuliah pulang). Tipikal dari individu atau kelompok mahasiswa ini dominan melewati hari-harinya di kampus (full) hanya dengan belajar (Teks

15 Janrico M.H. Manalu, 2014, Pedidikan Karakter Terhadap Pembentukan Perilaku Mahasiswa (Studi Kasus Proses Pendidikan Karakter, Ejournal Psikologi, Volume 2, Nomor 4, Sosiologi Universitas Mulawarman Kal-Tim, hlm. 26.
Book), mengerjakan semua yang diperintahkan setiap dosen dengan harapan kuliah dapat selesai tepat waktu dan meraih prestasi akademik yang memuaskan sehingga dapat menjadi dongkrak untuk peningkatan karier. Ciri khas utama kelompok ini adalah Indeks Prestasi Komulitatif (IPK) minded, cenderung eksklusif dan skeptisapatis terhadap apa pun bentuk aktivitas organisasi mahasiswa, senantiasa berpikir "neraca rugi-laba", saat diajak ber-organisasi bahkan cenderung subjektif dalam penilaiannya tentang aktivitas kampus.

2. Kelompok Mahasiswa Cheerleader, Kelompok atau tipikal individu semacam ini mempunyai beberapa ciri, di antaranya senang meramaikan atau ikut menyemarakkan beberapa kegiatan yang ada di kampus maupun organisasi mahasiswa. Namun, masih "alergi" jika suatu ketika dipercaya untuk mengemban 
Tanti Kirana Utami dan M. Rendi Aridhayandi Jurnal Hukum Mimbar Justitia Vol. 6 No. 1 - Juni 2020

amanah kepemimpinan ataupun kepengurusan dalam sebuah event dan kegiatan sosial keorganisasian. Bagi mahasiswa model ini, berkelompok dan berorganisasi haruslah ada muatan "pesta", bersenangsenang, sekadar pergaulan dan cenderung tidak mempunyai pendirian yang pasti terhadap pendapat-pendapat yang beredar mengelilingi lingkungan sekitarnya. Siapa yang dekatakrab, mereka-lah kawan "organisasinya."

3. Kelompok Mahasiswa Aktif dengan Organisasinya, Kelompok atau individu dari mahasiswa semacam ini tidak begitu dominan keberadaannya. Secara kuantitatif relatif sedikit, sedangkan dari segi kualitas masih harus dikaji ulang. Eksistensi kelompok atau individu bertipikal semacam ini sepintas aktif dengan segenap organisasi kemahasiwaan yang ada baik

yang intra maupun eksra
kampus. $^{16}$

\section{B. Regulasi Pendidikan Karakter di Fakultas Hukum Universitas Suryakancana.}

Kurikulum pendidikan tinggi adalah seperangkat rencana dan pengaturan mengenai isi, bahan kajian, maupun bahan pelajaran serta cara penyampaiannya, dan penilaian yang digunakan sebagai pedoman penyelenggaraan kegiatan pembelajaran di perguruan tinggi. ${ }^{17}$

Tanti mengemukakan Kirana

Utami Negara kesatuan Republik Indonesia merupakan Negara hukum berdasarkan Pancasila dan Undang-Undang Dasar Republik Indonesia Tahun 1945, yang memiliki tujuan mewujudkan kehidupan negara dan bangsa yang adil, sejahtera, aman, tentram, dan tertib, serta menjamin kedudukan hukum yang sama bagi masyarakat. Negara hukum yang dianut di Indonesia adalah negara hukum yang demokratis yang tercermin dalam

16 Ibid,. hlm. 28

17 Undang-Undang Nomor 12 Tahun 2012 tentang Pendidikan Tinggi. 
Tanti Kirana Utami dan M. Rendi Aridhayandi

Jurnal Hukum Mimbar Justitia

Vol. 6 No. 1 - Juni 2020

Undang-Undang Dasar 1945 Pasal 1

ayat (1) yang menyebutkan bahwa:

“Negara Indonesia adalah Negara

Kesatuan yang berbentuk Republik",

ayat (2) menyebutkan: "Kedaulatan

berada di tangan rakyat dan

dilaksanakan menurut Undang-Undang

Dasar, dan ayat (3)nya menyebutkan

bahwa: "Negara Indonesia adalah negara hukum" ${ }^{18}$

Negara Hukum adalah konsep yang merupakan produk sejarah. Karena itu unsur-unsur negara hukum mempunyai hubungan yang sangat erat dengan sejarah dan perkembangan masyarakat dari suatu negara. Sementara itu sejarah dan perkembangan masyarakat setiap negara tidaklah sama, sehingga pemaknaan dan unsur-unsur negara hukumnya juga berbeda. Hukum merupakan suatu alat untuk menjalankan sebuah negara melalui kekuasaan. ${ }^{19}$

18 Tanti Kirana Utami, 2013, Peran Serikat Pekerja Dalam Penyelesaian Perselisihan Pemutusan Hubungan Kerja, Jurnal Wawasan Hukum, Vol. 28 No. 1, Sekolah Tinggi Hukum Bandung, Bandung, hlm. 675. Dedi Mulyadi dan M. Rendi Aridhayandi,
Henny Nuraeny mengatakan bahwa then one as the deciding factor in holding power is the norm or law. ${ }^{20}$, Tujuan utama negara hukum adalah untuk menyelenggarakan ketertiban. ${ }^{21}$ Hukum yang merupakan sistem peraturan tidak akan tertib jika tanpa dukungan dari masyarakat. Tidak hanya peran lembaga saja.Peraturan tersebut memiliki sistem hukum yang menjadi tatanan di suatu negara. ${ }^{22}$

Pound lebih banyak menekankan arti dan fungsi pembentukan hukum yaitu bahwa hukum harus memajukan kepentingan umum. Statement inilah yang kemudian dikenal dengan teorinya

Tentang Pemilu Serentak Dihubungkan Dengan Pencegahan Korupsi Politik, Jurnal Hukum Mimbar Justitia, Vol. 1 No.2, Fakultas Hukum Universitas Suryakancana, Cianjur, hlm. 537.

20 Henny Nuraeny \& Tanti Kirana Utami, 2016, The Victim Handling Model of Human Trafficking through Economic Independence, Vol. 16 No. 2, FH-UNSOED, Purwokerto, hlm. 121.

21 Ahmad Hunaeny dan Tanti Kirana Utami, 2016, Perlindungan Hukum terhadap Pekerja dalam Pelaksanaan Hubungan Industrial, PJIH Volume 3 Nomor 2 Tahun 2016, FH-UNPAD, Bandung, hlm. 407.

22 Dwidja Priyatno dan M. Rendi Aridhayandi, 2016, Resensi Buku (Book Review) Satjipto Rahardjo, 2014, IImu Hukum, PT. Citra Aditya, Bandung, Jurnal Mimbar Justitia Vol. 2 No. 2, Fakultas Hukum Universitas Suryakancana, Cianjur, hlm. 883. 
Tanti Kirana Utami dan M. Rendi Aridhayandi Jurnal Hukum Mimbar Justitia Vol. 6 No. 1 - Juni 2020

"law as a tool of social engineering" (hukum sebagai alat atau sarana rekayasa/pembaharuan sosial). ${ }^{23}$

Menurut C.S.T Kansil, hukum mengabdi pada tujuan Negara yaitu mendatangkan kemakmuran dan kebahagiaan bagi rakyatnya. Tujuan negara tersebut dengan menyelenggarakan keadilan dan ketertiban. ${ }^{24}$

Untuk itu dalam pengelolaan penyelenggaraan pendidikan di Fakultas Hukum Universitas Suryakancana didasari oleh beberapa peraturan Perundang-undangan Program Studi Ilmu Hukum Fakultas Hukum Universitas Suryakancana adalah berpedoman pada:

1. Undang-Undang Nomor 20 Tahun 2003 Tentang Sistem Pendidikan Nasional.

23 A. Dwi Rachmanto, Wahyu Mijaya, Dewi Rohayati, Tumpal Napitupulu, M. Rendi Aridhayandi, 2016, Teori Hukum Lanjutan, Logoz Publishing, Bandung, hlm. 142-143.

24 M. Rendi Aridhayandi, 2019, Kewenangan Pemerintah Daerah Dalam Pembinaan dan Pengawasan Indikasi Geografis Beras Pandanwangi Cianjur, Disertasi, Program Pascasarjana Doktor Ilmu Hukum Universitas Katolik Parahyangan, Bandung, hlm. 2.
2. Undang-Undang Nomor 14 Tahun 2005 Tentang Guru dan Dosen.

3. Undang-Undang Nomor 12 Tahun 2012 Tentang Pendidikan Tinggi.

4. Peraturan Menteri Nomor 44 Tahun 2015 Tentang Standar Nasional Pendidikan Tinggi, yang telah di ubah dengan Permendikbud No. 3 Tahun 2020 Tentang Standar Nasional Pendidikan Tinggi.

Kurikulum memuat standar kompetensi lulusan yang mengacu pada Standar Nasional Perguruan Tinggi yang mencakup pengembangan kecerdasan intelektual, akhlak mulya, dan keterampilan yang terstruktur dalam kompetensi utama, pendukung dan lainnya yang mendukung terlaksananya Visi, Misi dan Tujuan Fakultas Hukum.

Kurikulum di Fakultas Hukum Universitas Suryakancana dirancang berdasarkan relevansinya dengan tujuan, cakupan dan kedalaman materi, pengorganisasian yang mendorong terbentuknya hard skills dan keterampilan kepribadian dan perilaku 
Tanti Kirana Utami dan M. Rendi Aridhayandi Jurnal Hukum Mimbar Justitia Vol. 6 No. 1 - Juni 2020

(soft skills) yang dapat diterapkan dalam berbagai situasi dan kondisi.

SK Dekan No 241/DekFH/UNSUR/Kep/XI/2016 tanggal 5 November 2016 Tentang Kompetensi Pendukung Lulusan Fakultas Hukum Universitas Suryakancana kompetensi ini sebagai salah satu suplemen Surat Keterangan Pendamping ljazah (SKPI), meliputi :

a. Memiliki kecakapan berbahasa Indonesia dengan baik.

b. Memiliki kecakapan berbahasa Inggris dengan baik yang dibuktikan melalui sertifikat TOEFL.

c. Mahir mengaplikasikan teknologi secara tepat, proporsional dan profesional.

d. Memiliki kecakapan dalam berorganisasi baik organisasi intra maupun extra kampus.

e. Memiliki jiwa kewirausahaan yang dibuktikan dengan sertifikat pelatihan USAID yang dilakukan secara berkala dan berkesinambungan, kompetensi Mahasiswa mengenai kewirausahaan juga dinaungi oleh
Unit Kegiatan Mahasiswa (UKM) Wira Usaha.

f. Memiliki jiwa kepemimpinan yang profesional.

g. Memiliki kemampuan dalam berargumentasi secara logis, kritis dan profesional.

Program Studi Ilmu Hukum Fakultas Hukum Universitas Suryakancana mempunyai Kompetensi yang dapat dipilih oleh lulusan sesuai SK Dekan No. 252.A/DEKFH/UNSUR/KEP/II/2017 tentang Penetapan Kompetensi Pilihan Lulusan Fakultas Hukum Universitas

Suryakancana. Menindaklanjuti

kebijakan tersebut di atas, salah satunya adalah mahasiswa diikutsetakan dalam pelatihan peningkatan soft skill dan keuangan atau Financial Life Skill (FLS).

Program FLS adalah suatu program yang dikembangkan oleh YouthWin Through Economic Participation dan didanai oleh USAID. Program ini bertujuan untuk memberdayakan pemuda Indonesia yang prasejahtera dan rentan (Poor and Vulnarable-P\&V) dengan menjalankan 


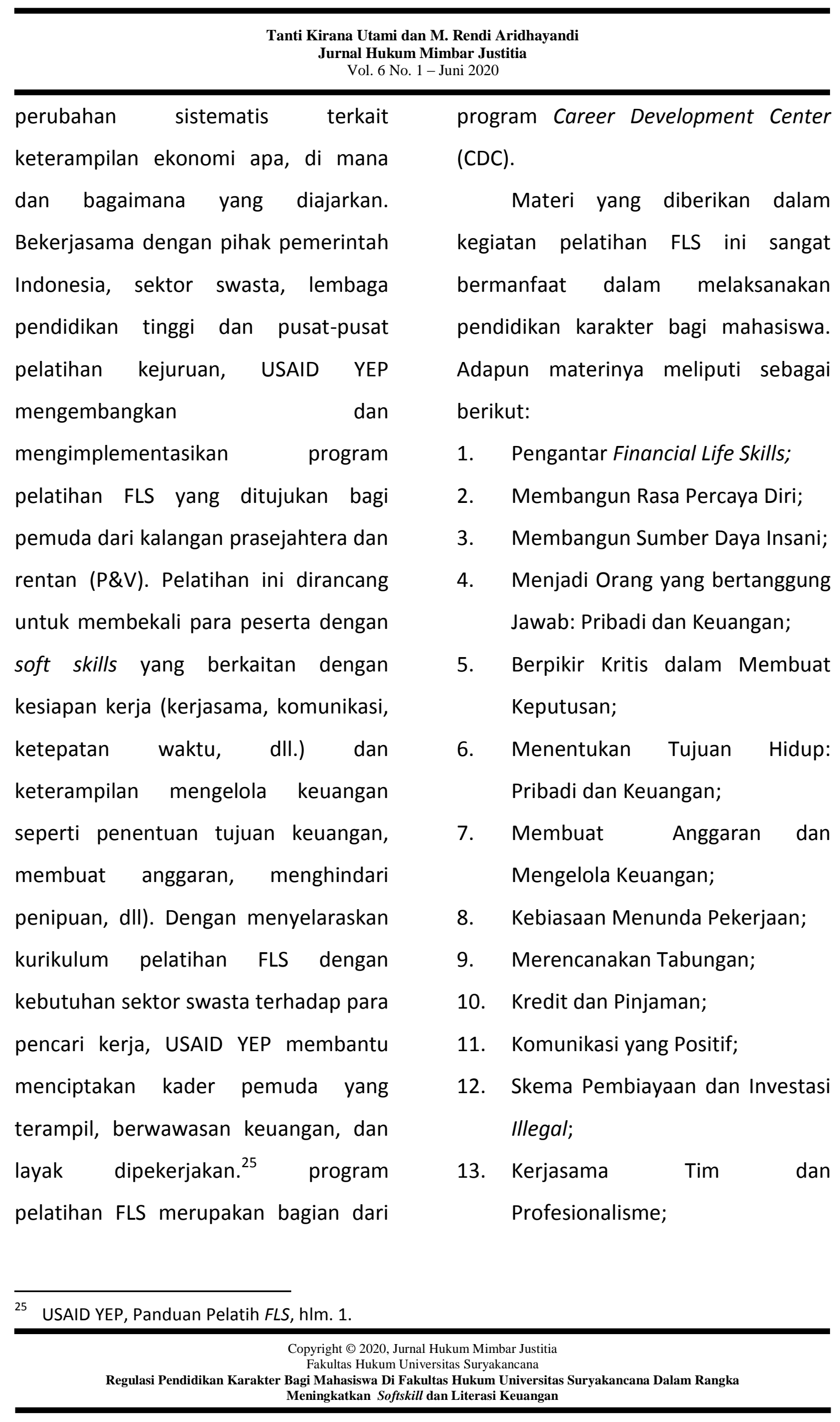


Tanti Kirana Utami dan M. Rendi Aridhayandi

Jurnal Hukum Mimbar Justitia

Vol. 6 No. 1 - Juni 2020

14. Membuat Rencana Aksi untuk Mencapai Tujuan Pribadi dan Keuangan.

Seluruh kegiatan Program Pelatihan FLS yang diselenggarakan oleh USAID KUNCI|YEP Project didanai oleh Badan Bantuan Internasional Amerika Serikat (USAID/Indonesia) di bawah kerjasama bilateral dengan Pemerintah Republik Indonesia, dan merupakan bagian dari program USAID KUNCl yang terfokus pada pembangunan tenaga kerja inklusif (Inclusive Workforce Development) bagi pemuda prasejahtera \& rentan di seluruh Indonesia.

Sebagai langkah awal, YEP telah melaksanakan rangkaian kegiatan Labor Market Assessment/LMA (Penilaian Pasar Kerja) di Jawa Barat. LMA bertujuan untuk menggali lebih dalam tentang kebutuhan pasar kerja sehubungan dengan keterampilan kerja, khususnya keterampilan diri (soft skill) dan literasi keuangan (financial literacy) yang mempengaruhi kinerja pemuda. Masukan dari pemangku kepentingan yang berasal dari pihak swasta, penyelenggara pelatihan $\begin{array}{lrr}\text { keterampilan } & \text { seperti } & \text { BLK, LKP, } \\ \text { pemerintah } & \text { daerah dan } & \text { Pendidikan } \\ \text { Tinggi } & \text { membantu } & \text { untuk }\end{array}$ memformulasikan kurikulum Pelatihan Financial Life Skills yang mengintegrasikan kurikulum pelatihan keterampilan diri (soft skill) dan literasi keuangan (financial literacy). ${ }^{26}$

Temuan LMA menggaris bawahi beberapa hal penting sebagai berikut:

1. Keterampilan sikap baik, interpersonal dan intra-personal merupakan prioritas pengusaha dalam merekruit tenaga kerja baru.

2. Pengusaha menilai bahwa kemampuan pekerja dalam mengelola keuangan sangatlah penting agar pekerja dapat melakukan tugas pekerjaan dengan baik.

3. Pengusaha menyebutkan bahwa pekerja yang memiliki permasalahan hutang piutang memiliki motivasi kerja yang rendah dan kurang berkonsentrasi dalam

${ }^{26}$ ToR kegiatan pelatihan FLS fase pendampingan, hlm. 1. 
Tanti Kirana Utami dan M. Rendi Aridhayandi Jurnal Hukum Mimbar Justitia

Vol. 6 No. 1 - Juni 2020

menyelesaikan tugas di tempat kerja.

4. Di sisi lain, para pemuda berasumsi bahwa pengusaha merekruit tenaga kerja hanya berdasarkan kemampuan teknis calon tenaga kerja saja. ${ }^{27}$

Berdasarkan hasil temuan Rapid Labor Market Assessment, USAID KUNCI|YEP Project menyusun langkah intervensi strategis demi membantu mengisi celah antara persepsi pengusaha juga pekerja tentang kesiapan dan keterampilan kerja yang dibutuhkan, termasuk:

1. Pengembangan kurikulum yang inovatif yang tujuan untuk meningkatkan keterampilan dalam membuat keputusan keuangan yang sehat (seperti tabungan, penganggaran, pengelolaan tunai, penggunaan kredit) demi mencapai kesejahteraan keuangan individu, bersamaan dengan penguatan kompetensi diri untuk kesiapsiagaan kerja (peningkatan kerjasama tim, pola pikir kritis, ketangkasan/kehandalan, berkomunikasi

efektif, menetapkan tujuan/goal-setting).

2. Penguatan Pelatih dan Sistem pelatihan yang bertujuan untuk meningkatkan keterampilan melatih berbasis pedagogical \& active learning serta mengembangkan proses pemantauan/monitoring dan evaluasi terstruktur untuk mendapatkan akurasi dampak program pelatihan di institusi/lembaga masing-masing.

3. Mengkondisikan agar para pemangku kepentingan yang berasal dari sektor swasta, pemerintah dan pemuda dapat mendukung dan mempromosikan kurikulum Pelatihan Keterampilan Hidup berbasis Keuangan serta memperluas cakupan wilayah di tingkat kabupaten, provinsi dan nasional. ${ }^{28}$

\section{PENUTUP}

1. Pendidikan karakter melalui pelatihan peningkatan soft skill 
Tanti Kirana Utami dan M. Rendi Aridhayandi Jurnal Hukum Mimbar Justitia Vol. 6 No. 1 - Juni 2020

dan keuangan bagi mahasiswa sangat penting sekali karena dalam Kegiatan Pelatihan tersebut mahasiswa dapat lebih meningkatkan keterampilan hidup (soft skills) dan keterampilan pengelolaan keuangan yang dapat mendukung kesiapan mahasiswa dalam memasuki pasar kerja maupun dunia usaha, yang kemudian dapat membantu meningkatkan kesejahteraan ekonominya di masa mendatang.

2. Regulasi terkait pelaksanaan pendidikan karakter bagi mahasiswa di Fakultas Hukum Universitas Suryakancana merujuk pada berbagai peraturan perundang-undangan yang berlaku, yang dtuangkan dalam bentuk surat keputusan Dekan mengenai kompetensi lulusan.

\section{DAFTAR PUSTAKA}

\section{A. Buku.}

A. Dwi Rachmanto, Wahyu Mijaya, Dewi Rohayati, Tumpal Napitupulu, M. Rendi Aridhayandi, 2016, Teori Hukum
Lanjutan, Logoz Publishing, Bandung.

Putra, Ikhsan S., dan Aryanti Pratiwi, 2005, Sukses dengan Soft Skills, ITB, Bandung.

\section{B. Peraturan Perundang-Undangan.}

Undang-Undang Dasar Negara Republik Indonesia Tahun 1945.

Undang-Undang Nomor 20 Tahun 2003 Tentang Sistem Pendidikan Nasional.

Undang-Undang Nomor 14 Tahun 2005 Tentang Guru dan Dosen.

Undang-Undang Nomor 12 Tahun 2012 Tentang Pendidikan Tinggi.

Peraturan Menteri Nomor 44 Tahun 87 2015 Tentang Standar Nasional Pendidikan Tinggi.

Permendikbud No. 3 Tahun 2020 Tentang Standar Nasional Pendidikan Tinggi.

C. Jurnal, Disertasi, Pidato Pengukuhan Guru Besar, Seminar, Internet.

Ahmad Hunaeny dan Tanti Kirana Utami, 2016, Perlindungan Hukum terhadap Pekerja dalam Pelaksanaan Hubungan Industrial, PJIH Volume 3 Nomor 2 Tahun 2016, FH-UNPAD, Bandung.

Dedi Mulyadi dan M. Rendi Aridhayandi, 2015, Putusan 
Mahkamah Konstitusi Tentang Pemilu Serentak Dihubungkan Dengan Pencegahan Korupsi Politik, Jurnal Hukum Mimbar Justitia, Vol. 1 No.2, Fakultas Hukum Universitas Suryakancana, Cianjur.

Devi Syukri Azhari Dan Alaren, 2017, Peran Dosen Dalam Mengembangkan Karakter Mahasiswa, Jutnal Pelangi, Vol. 9 No. 2.

Dwidja Priyatno dan M. Rendi Aridhayandi, 2016, Resensi Buku (Book Review) Satjipto Rahardjo, 2014, IImu Hukum, PT. Citra Aditya, Bandung, Jurnal Mimbar Justitia Vol. 2 No. 2, Fakultas Hukum Universitas Suryakancana, Cianjur.

Fatchul Mu`in, 2011, Pendidikan Karakter Konstruksi Teoritik \& Praktik, Ar-Ruzz Media, Yogyakarta, hlm. 11, vide dalam Firdaus, 2017, Urgensi Soft skill dan Character Building Bagi Mahasiwa, Jurnal TAPIs Vol. 14 No. 01.

Henny Nuraeny \& Tanti Kirana Utami, 2016, The Victim Handling Model of Human Trafficking through Economic Independence, Vol. 16 No. 2, FH-UNSOED, Purwokerto.

Isroah, Sukanti dan Ani Widayati, 2013, Implementasi Pendidikan Karakter Dalam Perkuliahan Perpajakan Pada Mahasiswa Jurusan Pendidikan Akuntansi,
Universitas Negeri Yogyakarta, Jurnal Pendidikan Akuntansi Indonesia, Vol. XI, No. 1.

Janrico M.H. Manalu, 2014, Pedidikan Karakter Terhadap Pembentukan Perilaku Mahasiswa (Studi Kasus Proses Pendidikan Karakter, Ejournal Psikologi, Volume 2, Nomor 4, Sosiologi Universitas Mulawarman Kal-Tim.

Jarot Tri Bowo Santoso, 2013, Karakter Dan Pemahaman Pendidikan Karakter Mahasiswa Pendidikan Akuntansi Melalui Pembelajaran Strategi Belajar Mengajar Berkarakter, Jurnal Pendidikan Ekonomi Dinamika pendidikan, Vol. VIII, No. 1, Juni.

Konstantinus Dua Dhiu dan Nikodemus Bate, 2017, Pentingnya Pendidikan Karakter Di Perguruan Tinggi Kajian Teoritis Praktis, 2nd Annual Proceeding, November, (ISSN: 2355-5106), STKIP Citra Bakti, Bajawa, NTT.

M. Rendi Aridhayandi, 2019, Kewenangan Pemerintah Daerah Dalam Pembinaan dan Pengawasan Indikasi Geografis Beras Pandanwangi Cianjur, Disertasi, Program Pascasarjana Doktor Ilmu Hukum Universitas Katolik Parahyangan, Bandung.

Sudrajat A., 2017, Psikologi Pendidikan, PE-AP Press, Kuningan, hlm. 25, vide dalam Firdaus, 2017, Urgensi Soft Skill dan Character Building 
Tanti Kirana Utami dan M. Rendi Aridhayandi Jurnal Hukum Mimbar Justitia

Vol. 6 No. 1 - Juni 2020

Bagi Mahasiwa, Jurnal TAPIs, Vol.

USAID YEP, Panduan Pelatih FLS.

14 No. 01 Januari - Juni.

Sukmawati dalam Monica Mayeni

Manurung dan Rahmadi, 2017, Identifikasi Faktor-Faktor

Pembentukan Karakter

Mahasiswa, Jurnal Analisis Sistem

Pendidikan Tinggi, VOL. 1 NO. 1 ,

Forum Dosen Indonesia.

Sukmawati F, 2016, Peran Kejujuran

Akademik (Academic Honesty)

dalam Pendidikan Karakter Studi

pada Mahasiswa Jurusan

Bimbingan Konseling Islam

Fakultas Ushuludin Adab dan

Dakwah Angkatan 2013/2014, Jurnal Khatulistiwa - Journal of Islamic Studies, Vol. 6 No. 1.

Susanti R, 2013, Penerapan Pendidikan Karakter di Kalangan Mahasiswa, Jurnal Al-Ta'lim, Vol. 1 No. 6.

Tanti Kirana Utami, 2013, Peran Serikat Pekerja Dalam Penyelesaian Perselisihan Pemutusan Hubungan Kerja, Jurnal Wawasan Hukum, Vol. 28 No. 1, Sekolah Tinggi Hukum Bandung, Bandung.

ToR kegiatan pelatihan FLS fase pendampingan. 